Tjalling C. Koopmans Research Institute

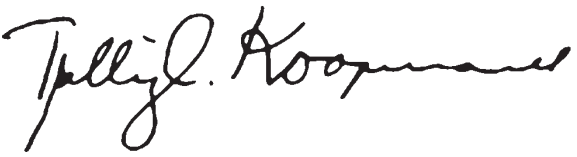

Discussion Paper Series nr: 08-02

\title{
Asymmetric substitutability: theory and some applications
}

Kris De Jaegher 


\section{Tjalling C. Koopmans Research Institute Utrecht School of Economics \\ Utrecht University}

Janskerkhof 12

3512 BL Utrecht

The Netherlands

telephone +31302539800

fax $\quad+31302537373$

website www.koopmansinstitute.uu.nl

The Tjalling C. Koopmans Institute is the research institute and research school of Utrecht School of Economics.

It was founded in 2003, and named after Professor Tjalling C. Koopmans, Dutch-born Nobel Prize laureate in economics of 1975.

In the discussion papers series the Koopmans Institute publishes results of ongoing research for early dissemination of research results, and to enhance discussion with colleagues.

Please send any comments and suggestions on the Koopmans institute, or this series to m.vandort@econ.uu.nl

ontwerp voorblad: WRIK Utrecht

\section{How to reach the authors}

Please direct all correspondence to the first author.

Kris De Jaegher

Utrecht University

Utrecht School of Economics

Janskerkhof 12

3512 BL Utrecht

The Netherlands

E-mail: k.dejaegher@econ.uu.nl 
Utrecht School of Economics

Tjalling C. Koopmans Research Institute

Discussion Paper Series 08-02

\title{
Asymmetric substitutability: theory and some applications
}

\author{
Kris De Jaegher \\ Utrecht School of Economics \\ Utrecht University \\ January 2008
}

\begin{abstract}
Economists usually describe goods as being either (gross) complements or (gross) substitutes. Yet, what is less known is that one good may be a gross substitute for a second good, while the second good is a gross complement to the first good. This paper shows the existence of asymmetric gross substitutability, and shows some potential examples and applications.
\end{abstract}

Keywords: asymmetric substitutability, consumer theory.

JEL classification: D11

\section{Acknowledgements}

I am grateful to two anonymous referees for helpful comments. Any remaining errors are my own 


\section{Introduction}

For the two-good case, economics textbooks predominantly classify goods as either being (gross) substitutes, or being (gross) complements. As is well known, when the cross-price derivative of the uncompensated demand for good 1 with respect to the price of good 2 is positive, then good 1 is a gross substitute for good $j$. When this cross-price derivative is negative, then good 1 is a gross complement to good 2 . However, what is less well known is that it is perfectly possible for good 1 to be a gross substitute for good 2, while good 2 is a gross complement to good 1 .

The possibility of cross-price effects with opposite sign in the case of two goods is mentioned by Hicks and Allen (1934b, p.213). In fact, Hicks and Allen use the apparent non-intuitiveness of this case as one more argument for their own concept of net substitutability, which is based on the cross-price derivate of compensated demand (i.e., demand keeping utility fixed, and excluding the effect of price changes on purchasing power). ${ }^{1}$ With compensated demand, one not only obtains cross-price derivatives with the same sign, but also with the same size. Thus, goods are necessarily symmetrically net substitutable: if good 1 is a substitute for good 2, then good 2 is necessarily also a substitute for good 1, and an equally strong substitute. A single measure, the elasticity of substitution, can then be used to measure the degree of substitutability between two goods.

Hicks and Allen's main reason for proposing the concept of net substitutability is the definition that was predominantly used for substitutes and complements in those days. $^{2}$ In the definition of Auspitz and Lieben (1889), two goods are gross complements when $\partial^{2} u / \partial x_{1} \partial x_{2}>0$ (the marginal utility of good $1, \partial u / \partial x_{1}$, increases when more of good 2 is bought), and are gross substitutes when $\partial^{2} u / \partial x_{1} \partial x_{2}<0$ (the marginal utility of good 1 decreases when more of good 2 is bought). However, this definition only makes sense within a cardinal view of utility. For instance, take the Cobb-Douglas utility function $u\left(x_{1}, x_{2}\right)=a \ln x_{1}+b \ln x_{2}$. We have $\partial^{2} u / \partial x_{1} \partial x_{2}=0$, and it can be checked that the two goods are indeed neither substitutes nor complements. Yet, this same preference mapping can also be represented by the utility function $v\left(x_{1}, x_{2}\right)=x_{1}{ }^{\mathrm{a}} x_{2}{ }^{\mathrm{b}}$, which has $\partial^{2} u / \partial x_{1} \partial x_{2}>0$. As $\partial^{2} u / \partial x_{1} \partial x_{2}$ represents a move from one indifference curve to another (with an interpretation of cardinal utility attached to it), Hicks and Allen propose the concept of net substitutability, which does not require a shift from one indifference curve to the other.

Yet, the contemporary definition of gross substitutability in terms of the sign of uncompensated demand does not require the concept of cardinal utility. It seems then that the only reason for not at least using gross substitutability side by side with net substitutability is that gross substitutability allows for the apparently unintuitive case of asymmetric substitutability. The purpose of this paper is to show that asymmetric gross substitutability is in fact an intuitive phenomenon, leading to deeper insight into consumer theory, and with many potential applications. Thus, while the argument in favor of net substitutability is that gross substitutability allows for asymmetric substitutability, our argument is that the disadvantage of net substitutability is that it does not allow for the concept of asymmetric substitutability.

\footnotetext{
${ }^{1}$ Nicholson (2005, pp.168-171), an exception among handbooks in mentioning the possibility of asymmetric gross substitutability, takes over the argument of Hick and Allen (1934).

${ }^{2}$ For an overview of the history of the complementarity and substitutability in economic theory see Lenfant $(2003,2006)$.
} 
Section 2 introduces two concepts of asymmetric gross substitutability, namely weak asymmetric gross substitutability, and strong asymmetric gross substitutability, and relates these two concepts to more familiar classifications of goods (namely luxuries and necessities, and elastic and inelastic goods). Section 3 gives two potential explanations for asymmetric gross substitutability in terms of Lancaster's (1966) approach to consumer theory and in terms of Gilley and Karels' (1991) constraints approach. Section 4 gives four potential examples/applications of asymmetric gross substitutability. We end with a discussion in Section 5.

\section{2. (A)symmetric substitutability: definition and existence}

\begin{tabular}{|l|l|l|l|}
\hline $\begin{array}{l}\text { Strong symmetric } \\
\text { gross substitutability }\end{array}$ & $\begin{array}{l}\text { Weak symmetric gross } \\
\text { substitutability }\end{array}$ & $\begin{array}{l}\text { Weak asymmetric gross } \\
\text { substitutability }\end{array}$ & $\begin{array}{l}\text { Strong asymmetric } \\
\text { gross substitutability }\end{array}$ \\
\hline$\partial x_{1}\left(p_{1}, p_{2}, m\right) / \partial p_{2}=$ & $\operatorname{sgn} \partial x_{1}\left(p_{1}, p_{2}, m\right) / \partial p_{2}=$ & $\partial x_{1}\left(p_{1}, p_{2}, m\right) / \partial p_{2} \neq$ & $\operatorname{sgn} \partial x_{1}\left(p_{1}, p_{2}, m\right) / \partial p_{2} \neq$ \\
$\partial x_{2}\left(p_{1}, p_{2}, m\right) / \partial p_{1}$ & $\operatorname{sgn} \partial x_{2}\left(p_{1}, p_{2}, m\right) / \partial p_{1}$ & $\partial x_{2}\left(p_{1}, p_{2}, m\right) / \partial p_{1}$ & $\operatorname{sgn} \partial x_{2}\left(p_{1}, p_{2}, m\right) / \partial p_{1}$ \\
& & & \\
\hline
\end{tabular}

Table 1: Symmetric and asymmetric gross substitutability

Our focus is on the two-good case. For $i=1,2$, denote by $x_{i}$ the uncompensated, Marshallian demand for good $i$, by $p_{i}$ the price of good $i$, and by $m$ the consumer's income. Good 1 is a gross substitute for good 2 if $\partial x_{1}\left(p_{1}, p_{2}, m\right) / \partial p_{2}>0$, and good 1 is a gross complement to good 2 if $\partial x_{1}\left(p_{1}, p_{2}, m\right) / \partial p_{2}<0$. For the two-good case, microeconomic textbooks usually without further describe goods as being gross substitutes, or being gross complements. This suggests then that goods are either what we call weak symmetric gross substitutes, meaning that $\operatorname{sgn} \partial x_{1}\left(p_{1}, p_{2}, m\right) / \partial p_{2}=\operatorname{sgn} \partial x_{2}\left(p_{1}, p_{2}, m\right) / \partial p_{1}$, or even what we call strong symmetric gross substitutes, meaning that $\partial x_{1}\left(p_{1}, p_{2}, m\right) / \partial p_{2}=\partial x_{2}\left(p_{1}, p_{2}, m\right) / \partial p_{1}$, as summarized in the first two columns of Table $1 .^{3}$

However, two goods can also exhibit asymmetric gross substitutability, which we define in the following way. A strong criterion for asymmetric gross substitutability is that $\operatorname{sgn} \partial x_{1}\left(p_{1}, p_{2}, m\right) / \partial p_{2} \neq \operatorname{sgn} \partial x_{2}\left(p_{1}, p_{2}, m\right) / \partial p_{1}$; this we refer to as strong asymmetric gross substitutability (see again Table 1 for a summary). While our main focus is on strong asymmetric substitutability, we also introduce a weak criterion for asymmetric gross substitutability, where it suffices that $\partial x_{1}\left(p_{1}, p_{2}, m\right) / \partial p_{2} \neq$ $\partial x_{2}\left(p_{1}, p_{2}, m\right) / \partial p_{1}$; we refer to this as weak asymmetric gross substitutability. The interest of the latter concept of asymmetric substitutability is that it can directly be related to income effects. Note that goods that exhibit strong asymmetric gross substitutability necessarily exhibit weak asymmetric gross substitutability, while the reverse is not true. We now consecutively derive claims that give insight into the circumstances under which weak and strong asymmetric gross substitutability occur. We show that these circumstances are familiar. Weak asymmetric gross substitutability fully coincides with the case where one good is a luxury and the other

\footnotetext{
${ }^{3}$ In our concept of symmetric and asymmetric substitutability, we use cross-price level effects rather than cross-price elasticities. As we are comparing two level effects, we do not need elasticities to make our concept of cross-price effects unit-free (see Hicks and Allen, 1934b, p.213 for this argument). In a similar argument, Sethuraman et al. (1999) argue that it is better to compare absolute cross-price effects than to compare cross-price elasticities, as the latter are affected by budget shares.
} 
good is a necessity; strong asymmetric gross substitutability fully coincides with the case where one good is price elastic (the complement) and the other good is price inelastic (the substitute).

\subsection{Weak asymmetric gross substitutability}

Denote $\varepsilon_{x_{i} m}=\left(m / x_{i}\right)\left(\partial x_{i} / \partial m\right)$ as the income elasticity of $\operatorname{good} i$, for $i=1,2$. Good $i$ is called a luxury if $\varepsilon_{x_{i} m}>1$, and is called a necessity if $\varepsilon_{x_{i} m}<1$; good 1 is called an inferior good if $\varepsilon_{x_{i} m}<0$. Denote as $s_{i}=\left(p_{i} x_{i}\right) / m$ the consumer's budget share spetnt on good $i$, where $s_{1}+s_{2}=1$. By totally differentiating the budget constraint $p_{1} x_{1}+p_{2} x_{2}=m$ with respect to $m$, one obtains that $s_{1} \varepsilon_{x_{1} m}+s_{2} \varepsilon_{x_{2} m}=1$. It follows that, if good 1 is a necessity or an inferior good, then good 2 must be a luxury. Homothetic preferences are preferences such that $\varepsilon_{x_{1} m}=\varepsilon_{x_{2} m}=1$ (goods are neither necessities, nor luxuries). Non-homothetic preferences are preferences such that $\varepsilon_{x_{1} m} \neq \varepsilon_{x_{2} m}$.

Claim 1 now shows that there is a one-to-one relationship between weak asymmetric gross substitutability and non-homothetic preferences. ${ }^{4}$

\section{Claim 1:}

In the two-good case, preferences that exhibit weak asymmetric substitutability are synonymous with non-homothetic preferences. In particular, $\partial x_{1}\left(p_{1}, p_{2}, m\right) / \partial p_{2}>$ $\partial x_{2}\left(p_{1}, p_{2}, m\right) / \partial p_{1}$ if and only if good 1 is a necessity or an inferior good, and good 2 is a luxury.

One way to show Claim 1 is to look at the Hicksian decomposition of the crossprice effects ${ }^{5}$ :

$$
\begin{aligned}
& \frac{\partial x_{1}}{\partial p_{2}}=\frac{\partial h_{1}}{\partial p_{2}}-\frac{\partial x_{1}}{\partial m} x_{2} \\
& \frac{\partial x_{2}}{\partial p_{1}}=\frac{\partial h_{2}}{\partial p_{1}}-\frac{\partial x_{2}}{\partial m} x_{1}
\end{aligned}
$$

where $h_{1}\left(p_{1}, p_{2}, m\right)$ denotes compensated, Hicksian demand for good 1 (= demand compensating the consumer for the loss in purchasing power from the price increase

\footnotetext{
${ }^{4}$ Allenby and Rossi (1991) provide a similar link between asymmetric switching between brands, and non-homothetic preferences.

${ }^{5}$ An alternative proof, that does not involve Slutsky equations, is the following. We now that, in order to have unit income elasticity, the demand for good 1 must take the form $x_{1}=m f\left(p_{1}, p_{2}\right)$. We also know that this demand should be homogenous of degree 1 (otherwise, it would matter in which units we measure demand), meaning that we are able to rewrite the demand as $x_{1}=m / p_{1} f\left(1, p_{2} / p_{1}\right)$, or in short $x_{1}=m / p_{1} f\left(p_{2} / p_{1}\right)$. It follows that $\partial x_{1} / \partial p_{2}=m / p_{1} f^{\prime}\left(p_{2} / p_{1}\right)\left(1 / p_{1}\right)$. Using the budget constraint and the above demand function, we have $x_{2}=m / p_{2}\left[1-f\left(p_{2} / p_{1}\right)\right]$. It follows that $\partial x_{2} / \partial p_{1}=m / p_{2}\left[-f^{\prime}\left(p_{2} / p_{1}\right)\right]\left(-p_{2} / p_{1}^{2}\right)$. But this is the same result as obtained above for $\partial x_{1} / \partial p_{2}$.
} 
such that his or her utility remains constant). Good 1 is a net substitute for good 2 if $\partial h_{1}\left(p_{1}, p_{2}, m\right) / \partial p_{2}>0$, and good 1 is a net complement for good 2 if $\partial h_{1}\left(p_{1}, p_{2}, m\right) / \partial p_{2}<0$. As is well known for the two-good case, the symmetry of the Slutsky matrix tells us that $\partial h_{1}\left(p_{1}, p_{2}, m\right) / \partial p_{2}=\partial h_{2}\left(p_{1}, p_{2}, m\right) / \partial p_{1}$, meaning that in the two-good case, we always have strong symmetric net substitutability. Subtracting (2) from (1), and using the equality of the Hicksian cross-price effects, we obtain that

$$
\frac{\partial x_{1}}{\partial p_{2}}-\frac{\partial x_{2}}{\partial p_{1}}=\frac{\partial x_{2}}{\partial m} x_{1}-\frac{\partial x_{1}}{\partial m} x_{2}
$$

It follows by (3) that $\left(\partial x_{1} / \partial p_{2}\right)>\quad\left(\partial x_{1} / \partial p_{2}\right) \Leftrightarrow \quad \varepsilon_{x_{2} m}>\varepsilon_{x_{1} m}$, and that $\left(\partial x_{1} / \partial p_{2}\right)=\left(\partial x_{1} / \partial p_{2}\right) \Leftrightarrow \varepsilon_{x_{2} m}=\varepsilon_{x_{1} m}$. Thus, weak asymmetric substitutability is a synonym for asymmetric income elasticity. ${ }^{6}$ Intuitively, if a necessity and a luxury are mutual substitutes, then the necessity is a stronger substitute for the luxury than the luxury is for the necessity; bread can be a substitute for yachts, but yachts cannot easily be a substitute for bread. ${ }^{7}$

Further insight into the one-to-one relation between weak asymmetric gross substitutability and non-homothetic preferences can be obtained in the following way. Let us look at the effect of an increase in income on $\left(x_{2} / x_{1}\right)$. With homothetic preferences, this effect must be zero; if good 1 is a necessity and good 2 a luxury, then this effect must be positive; if good 1 is a luxury and good 2 is a necessity, this effect must be negative. An increase in income can now be decomposed into a decrease of both prices with the same percentage. Thus, in order to increase income, we decrease both prices such that the relative price remains the same. In particular, fix $p_{2}=v p_{1}$, so that we can rewrite $\left(x_{2} / x_{1}\right)$ as $x_{2}\left(p_{1}, v p_{1}, m\right) / x_{1}\left(p_{1}, v p_{1}, m\right)$. Then

$$
\frac{\partial\left(x_{2} / x_{1}\right)}{\partial m}=\frac{\partial\left(x_{2} / x_{1}\right)}{\partial p_{1}}+v \frac{\partial\left(x_{2} / x_{1}\right)}{\partial p_{2}}
$$

where

$$
\begin{aligned}
& \frac{\partial\left(x_{2} / x_{1}\right)}{\partial p_{1}}=\frac{x_{1} \partial x_{2} / \partial p_{1}-x_{2} \partial x_{1} / \partial p_{1}}{x_{1}^{2}} \\
& v \frac{\partial\left(x_{2} / x_{1}\right)}{\partial p_{2}}=v \frac{x_{1} \partial x_{2} / \partial p_{2}-x_{2} \partial x_{1} / \partial p_{2}}{x_{1}^{2}} .
\end{aligned}
$$

\footnotetext{
${ }^{6}$ This point generalizes to the case of more than two goods, with the exception that two goods that are asymmetric gross substitutes may both be necessities, and may both be luxuries. In order to have asymmetric substitutability, it suffices that one luxury is a luxury to a lesser extent than the other luxury, or that one necessity is a necessity to a lesser extent than the other necessity.

${ }_{7}$ This result reflects the Hicksian decomposition of cross-price effects into substitution and income effects. From the point of view of Hicks and Allen (1934), only the substitution effect, which is necessarily symmetric, measures the substitutability between goods. This is why weak asymmetric gross substitutability is synonymous with asymmetric income elasticity; since net substitutability is symmetric, asymmetric gross substitutability is purely a product of the income effects. Yet, for all practical purposes, the degree to which substitutes are available for a good is measured by the uncompensated cross-price effect, and the income effect makes out an integer part of this effect.
} 
Given that we have only two goods, using the budget line, one obtains that

$$
\begin{aligned}
& \partial x_{1} / \partial p_{1}=-x_{1} / p_{1}-p_{2} / p_{1} \partial x_{2} / \partial p_{1} \\
& \partial x_{2} / \partial p_{2}=-x_{2} / p_{2}-p_{1} / p_{2} \partial x_{1} / \partial p_{2}
\end{aligned}
$$

Substituting these values into (5) and (6), using the fact that $v=p_{2} / p_{1}$, and reworking, one obtains that

$$
\begin{aligned}
& \frac{\partial\left(x_{2} / x_{1}\right)}{\partial p_{1}}=\frac{m \partial x_{2} / \partial p_{1}+x_{1} x_{2} / p_{1}}{p_{1} x_{1}^{2}} \\
& v \frac{\partial\left(x_{2} / x_{1}\right)}{\partial p_{2}}=-\frac{m \partial x_{1} / \partial p_{2}+x_{1} x_{2} / p_{1}}{p_{1} x_{1}^{2}}
\end{aligned}
$$

Plugging (9) and (10) into (4), it follows that

$$
\frac{\partial\left(x_{2} / x_{1}\right)}{\partial m}=\frac{\partial\left(x_{2} / x_{1}\right)}{\partial p_{1}}+v \frac{\partial\left(x_{2} / x_{1}\right)}{\partial p_{2}}>=<0 \text { iff } \frac{\partial x_{2}}{\partial p_{1}}>=<\frac{\partial x_{1}}{\partial p_{2}} .
$$

This is illustrated in Figure 1, where it is shown that equation (4) can be seen as decomposing an income decrease into an increase of both prices that leaves the slope of the budget line unchanged. Figure 1a represents homothetic preferences. With strong symmetric gross substitutability (meaning that the cross-price effects, indicated as $\Delta x_{1}$ and $\Delta x_{2}$, are equal), $\left(x_{2} / x_{1}\right)$ is unchanged, meaning that the income offer curve is a line through the origin, and that we have homothetic preferences. With weak asymmetric gross substitutability, where $\left(\partial x_{1} / \partial p_{2}\right)>\left(\partial x_{2} / \partial p_{1}\right)$ (reflected in the fact that $\left.\Delta x_{1}>\Delta x_{2}\right)$, good 1 is a necessity, and good 2 is a luxury, as represented in Figure $1 b$.

As can be seen in Figure 1b, with non-homothetic preferences, the indifference curves "fan out". For given levels of good 1, the distance between indifference curves does not change that much as one moves from one indifference curve to the other. However, for given levels of good 2, the distance between indifference curves changes sharply as one moves from one indifference curve to the other. This is formalized in the Appendix to this paper, which shows that in the case of weak asymmetric gross substitutability (where $\left.\left(\partial x_{1} / \partial p_{2}\right)>\left(\partial x_{2} / \partial p_{1}\right)\right)$, the curvature of the utility function in terms of good 1 must be large relative to the curvature of the utility function in terms of good 2. Intuitively, the marginal utility of a necessity (good 1) decreases more sharply than the marginal utility of a luxury (good 2). 
(a)

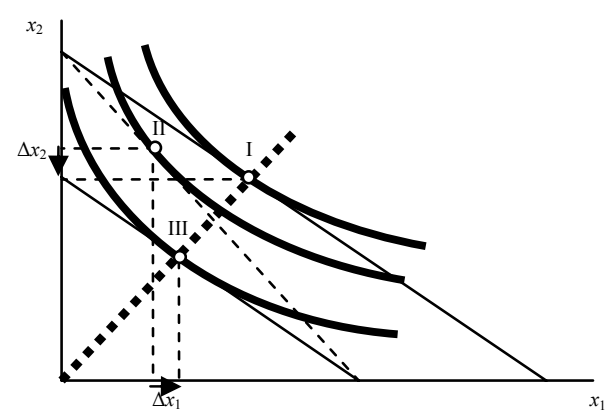

(b)

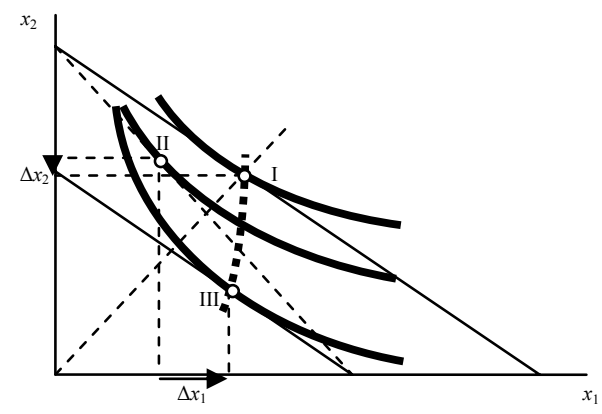

Figure 1: Decomposition of income decrease into increase in price of both goods that leaves slope unchanged. As shown in panel (a), if the cross-price effects are equal, we have homothetic preferences. As shown in panel (b), if good 1 is a stronger substitute for good 2 then good 2 is for good 1 , then good 1 is a necessity, and good 2 is a luxury.

\subsection{Strong asymmetric gross substitutability}

The following claim gives insight into the phenomenon of strong asymmetric gross substitutability (see Table 1):

Claim 2: Consider the case where goods 1 and 2 exhibit strong asymmetric gross substitutability, namely where good 1 a substitute for good 2, and where good 2 a complement to good 1.

(i) A necessary but not sufficient condition for such strong asymmetric substitutability is that good 1 is a necessity or an inferior good, and that good 2 is a luxury.

(ii) Such strong asymmetric substitutability is more likely to be obtained as good 1 is a necessity to a higher degree (good 2 is a luxury to a higher degree), as the budget share of good 2 decreases, and as the Hicksian cross-price elasticities are smaller.

(iii) Such strong asymmetric substitutability exists if and only if good 1 is price inelastic, and good 2 is price elastic.

As all goods that exhibit strong asymmetric gross substitutability also exhibit weak asymmetric gross substitutability, it follows that it is a necessary condition for strong asymmetric gross substitutability that one good is a necessary or an inferior good, and that the other good is a luxury. To see that this is not a sufficient condition, we now rewrite (1) and (2) as elasticities:

$$
\begin{aligned}
& \varepsilon_{x_{1} p_{2}}=\varepsilon_{h_{1} p_{2}}-s_{2} \varepsilon_{x_{1} m} \\
& \varepsilon_{x_{2} p_{1}}=\varepsilon_{h_{2} p_{1}}-s_{1} \varepsilon_{x_{2} m},
\end{aligned}
$$

where $\varepsilon_{x_{i} p_{j}}=\left(p_{j} / x_{i}\right)\left(\partial x_{i} / \partial p_{j}\right)$ is the uncompensated cross-price elasticity of good $i$, for $i=1,2$ and $j \neq i$; similarly, $\varepsilon_{h_{i} p_{j}}$ is the compensated (Hicksian) cross-price 
elasticity. Note that our measure for asymmetric substitutability continues to be in terms of the levels of the cross-price effects, and not the elasticities. However, for the concept of asymmetric gross substitutability, where it is the sign of the cross-price effects that matters, it does not matter whether we use levels of elasticities. The point of (12) and (13) is that looking at cross-price elasticities leads to useful additional insights. It is clear from expressions (12) and (13) that $\varepsilon_{x_{1} m}<1, \varepsilon_{x_{2} m}>1$ is not a sufficient condition for strong asymmetric substitutability. When good 1 is a necessity or an inferior good, and when good 2 is a luxury, strong asymmetric gross substitutability is more likely as the budget share of good 2 gets smaller, and as the Hicksian cross-price elasticities get smaller.

To see the third part of Claim 2, rewrite equations (7) and (8) as elasticities, to obtain:

$$
\begin{aligned}
& \varepsilon_{x_{1} p_{1}}=-1-\frac{s_{2}}{s_{1}} \varepsilon_{x_{2} p_{1}} \\
& \varepsilon_{x_{2} p_{2}}=-1-\frac{s_{1}}{s_{2}} \varepsilon_{x_{1} p_{2}},
\end{aligned}
$$

where $\varepsilon_{x_{i} p_{i}}=\left(p_{i} / x_{i}\right)\left(\partial x_{i} / \partial p_{i}\right)$ is the uncompensated own-price elasticity of good $i$. It follows directly from (14) and (15) that strong asymmetric substitutability, where good 1 is a substitute for good 2, and good 2 is a complement to good 1, is synonymous with good 1 being price inelastic, and good 2 being price elastic. Clearly, the demand for a good is price inelastic if there are no good substitutes available for it, and the demand for a good is price elastic if good substitutes are available for it. ${ }^{8}$

\section{Asymmetric substitutability: intuitions}

The previous section shows the existence of asymmetric substitutability, in showing that weak asymmetric gross substitutability is synonymous with non-homothetic preferences, and that (in the two-good case) strong asymmetric gross substitutability is synonymous with one good being price elastic, and the other good being price inelastic. However, the standard intuition about two goods being substitutes or complements relates to some physical aspect of the goods at hand. Blue pencils and black pencils are substitutes because most people do not care too much whether they write in black or blue. Left shoes and right shoes are complements because one shoe

\footnotetext{
${ }^{8}$ The extension to multiple goods is more subtle. Consider the case of three goods. Equations (14) and (15) now become $\varepsilon_{x_{1} p_{1}}=-1-\frac{s_{2}}{s_{1}} \varepsilon_{x_{2} p_{1}}-\frac{s_{3}}{s_{1}} \varepsilon_{x_{3} p_{1}}$ and $\varepsilon_{x_{2} p_{2}}=-1-\frac{s_{1}}{s_{2}} \varepsilon_{x_{1} p_{2}}-\frac{s_{3}}{s_{2}} \varepsilon_{x_{3} p_{2}}$. Let goods 1 and 2 be weak or strong symmetric substitutes (see Table 1 for these concepts). However, let good 3 be a complement to good $1\left(\varepsilon_{x_{3} p_{1}}<0\right)$, and let good 3 be a substitute for $\operatorname{good} 2\left(\varepsilon_{x_{3} p_{2}}>0\right)$. Then even though goods 1 and 2 are symmetric substitutes, it may be that the demand for good 1 is price inelastic (because it has a complement in good 3), and that the demand for good 2 is price elastic (because it has a substitute in good 3). Thus, in the multiple-good case, the argument that for a pair of goods 1 and 2, relatively inelastic demand for good 1 and elastic demand for the good 2 points towards asymmetric substitutability is only maintained if other goods are all substitutes to goods 1 and 2 , or are all complements to goods 1 and 2 .
} 
is of little use. Can we find similar intuitions for in particular strong asymmetric substitutability?

We now state two additional intuitions about the determinants of asymmetric gross substitutability. These are based on Lancaster's approach to consumer theory (1966), which argues that we do not directly have preferences over goods, but instead have preferences over certain characteristics, which are produced using goods. In particular, let the consumer's utility be a function of two characteristics $C_{1}$ and $C_{2}$, and let good 1 and good 2 be inputs in producing each of these characteristics.

$$
U=u\left\{C_{1}\left(x_{1}, x_{2}\right), C_{2}\left(x_{1}, x_{2}\right)\right\}
$$

\subsection{Consumers consume two characteristics, and one characteristic gets more weight as utility is lowered.}

Let $U$ take on the form $U=\min \left\{\alpha C_{1},(1-\alpha) C_{2}\right\}$, so that the two characteristics are perfect complements. The weight $\alpha$, with $0<\alpha<1$, determines the relative importance that the consumer attaches to characteristic 1. Let the two goods be perfect substitutes in producing the two characteristics, with $C_{1}=\left(a x_{1}+b x_{2}\right)$, and $C_{2}=\left(c x_{1}+d x_{2}\right)$. Let good 1 be better at producing characteristic 1 and let good 2 be better at producing characteristic 2, i.e. let $a>c$ and $d>b$. Moreover, let $\alpha a>(1-\alpha) c$ and let $(1-\alpha) d>\alpha b$, meaning that the contribution to utility by good 1 is larger through characteristic 1 than through characteristic 2 ; for good 2 the reverse is the case.

Consider two utility levels $U_{1}, U_{2}$, with $U_{2}<U_{1}$. For utility level $U_{1}$ we have

$$
\min \left\{\alpha_{1}\left(a x_{1}+b x_{2}\right),\left(1-\alpha_{1}\right)\left(c x_{1}+d x_{2}\right)\right\}
$$

For utility level $U_{2}$, we have

$$
\min \left\{\alpha_{2}\left(a x_{1}+b x_{2}\right),\left(1-\alpha_{2}\right)\left(c x_{1}+d x_{2}\right)\right\}
$$

with $\alpha_{2}>\alpha_{1}$. This means that for the lower utility level $U_{2}$, characteristic 1 (the characteristic that good 1 is the best at producing) is relatively more important to the consumer. Two indifference curves $U_{1}$ and $U_{2}$ that are in accordance with these assumptions are represented in Figure 3. As shown in Figure 3a, good 1 is a gross substitute for good 2, and as shown in Figure 3b, good 2 is a gross complement to good 1 . 
(a)

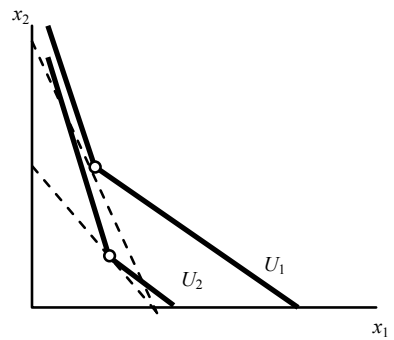

(b)

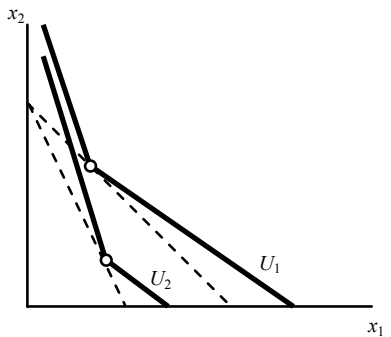

Figure 3 Characteristic 1 becomes more important as utility is decreased

But why would characteristic 1 become relatively more important as utility decreases? A simple intuition can be provided using Gilley and Karels (1991) constraint approach. Suppose that the consumer needs a certain minimum amount of characteristic 1 in order to survive, meaning that

$$
a x_{1}+b x_{2} \geq \bar{C}_{1}
$$

Equation (19) can be seen as a subsistence constraint (the solid dashed line in Figures $4 \mathrm{~b}$ and $5 \mathrm{~b}$, indicated as $S$ ). The consumer's choice now proceeds in two steps. The first and standard step is to look for the bundle such that the highest indifference curve is reached given the budget line (bundle I for budget line $B_{1}$, and bundle II for budget line $B_{2}$ in Figures $4 \mathrm{a}$ and 5a). The second step is to look whether the bundle lies above or below the subsistence constraint $S$. If it lies above, then it is the optimal bundle (as is the case for bundle I in Figures 4 and 5). If not (as is the case for bundle II in Figures $4 \mathrm{a}$ and 5a, which lies below $S$ ), then the consumer looks for the bundle such that the highest indifference curve is reached, given that the bundle should not lie above the budget constraint, and should not lie below the subsistence constraint. For budget line $B_{2}$ in Figures $4 \mathrm{~b}$ and $5 \mathrm{~b}$, allowable bundles are those below budget line $B_{2}$ and above constraint $S$, yielding the gray area. The consumer then chooses bundle III. Thus, in Figures $4 \mathrm{a}$ and 5a, goods 1 and 2 appear to be mutual gross complements. However, as illustrated in Figure 4b, close to the subsistence constraint, good 1 becomes a gross substitute for good 2, and serves to assure that the consumer can subsist. As illustrated in Figure 5b, good 2 remains a gross complement to good 1. 
(a)

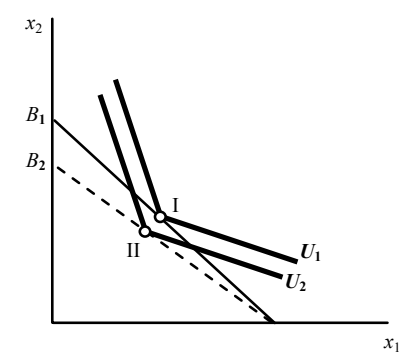

(b)

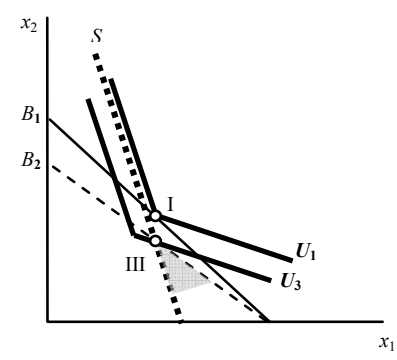

Figure 4 Subsistence constraint: increase in the price of good $2-\operatorname{good} 1$ is a substitute for good 2.

(a)

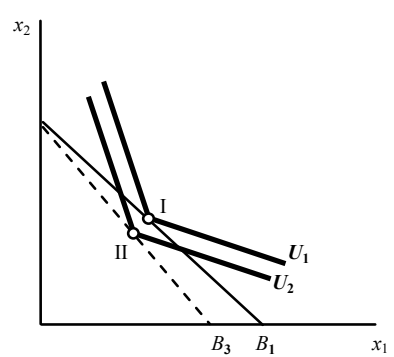

(b)

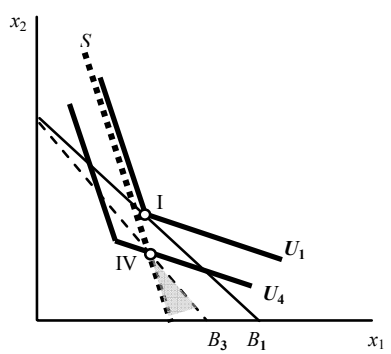

Figure 5 Subsistence constraint: increase in the price of good $1-\operatorname{good} 2$ is a complement to good 1 .

The relation between the analysis in Figure 3 on the one hand, and Figures 4 and 5 on the other hand, is the following. If we want to integrate the subsistence constraint directly into the consumer's preferences ${ }^{9}$, then subsistence needs to receive more weight as utility decreases. Only then do the consumer's optimal bundles allow her to maintain the same level of subsistence. The analysis in Figure 3 can thus be seen as a more general case, where subsistence becomes relatively more important as utility decreases, and some approximate subsistence level is thereby achieved.

\subsection{Good 1 is a substitute for good 2 only when utility is low}

Let $U$ take on the form $U=\min \left\{C_{1}, C_{2}\right\}$, and let characteristics $C_{1}$ and $C_{2}$ each be linear in good 1 and good 2. In particular, consider two utility levels $U_{1}, U_{2}$, with $U_{1}<U_{2}$. Consider the following two indifference curves. For utility level $U_{2}$ we have

$$
\min \left\{a x_{1}, d x_{2}\right\}
$$

where $a>d$. For utility level $U_{1}$, we have

\footnotetext{
${ }^{9}$ Wichers (1994) criticizes Gilley and Karels' (1991) approach on the grounds that the subsistence constraint should be directly part of the consumer's preferences.
} 


$$
U_{1}=\min \left\{a x_{1}, c x_{1}+d x_{2}\right\}
$$

where $a>c$. The left part of Figure 6 shows that good 1 can be a gross substitute for good 2: if the price of good 2 rises, the consumer consumes more of good 2 . The right part of Figure 6 shows that good 2 is a gross complement to good 1: if the price of good 1 rises, the consumer buys more of good 2 .

(a)

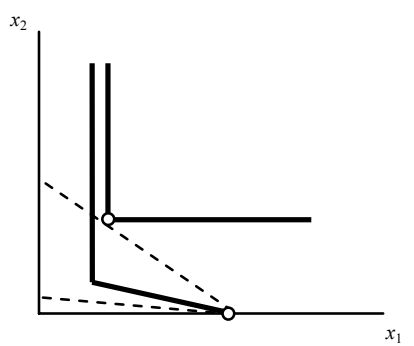

(b)

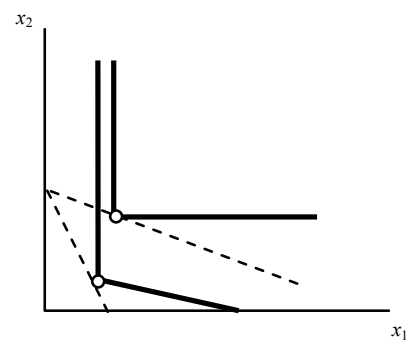

Figure 6

In order to explain why good 1 becomes a substitute for good 2 only when utility is low, consider the following case. Assume that good 1 can produce both characteristics, but good 2 can only produce characteristic 2 . Contrary to what was implicitly assumed in all previous cases in Section 3, assume that a unit of a good used to produce characteristic 1 does not at the same time contribute to the production of characteristic 2. Denote by $x_{1, I}$ the amount of good 1 used to produce characteristic 1 , and let

$$
\begin{aligned}
& C_{1}=\alpha x_{1, I} \\
& C_{2}=\gamma\left(x_{1}-x_{1, I}\right)+\delta x_{2} .
\end{aligned}
$$

The two characteristics $C_{1}$ and $C_{2}$ are perfect complements. While it is also possible to produce characteristic 2 by using good 1, the consumer as such prefers to use good 1 exclusively for the production of characteristic 1 . Thus, the consumer also considers goods 1 and 2 as perfect complements:

$$
U=\min \left\{\alpha x_{1}, \delta x_{2}\right\}
$$

In Figures 6 and 7, indifference curve $U_{1}$ is flat to the right of $x_{1}$. Extra units of good 1 are not normally used for the production of characteristic 1, and therefore do not normally increase utility. However, assume that the consumer at the same time wants to achieve at least a minimal level of characteristic $1\left(C_{1} \geq \overline{C_{1}}\right)$, as well as a minimal level of characteristic $2\left(C_{2} \geq \bar{C}_{2}\right)$.

The consumer's choice can now again be seen as consisting of two steps. The first step consists of looking for highest indifference curve that can be achieved for given budget lines such as $B_{1}$ and $B_{2}$ in Figures $6 \mathrm{a}$ and $7 \mathrm{a}$, leading to candidate optimal bundles I and II - where again good 1 (2) is only used to produce characteristic 1 (2). From this perspective, goods 1 and 2 are mutual gross complements, as indicated in Figures $6 \mathrm{a}$ and $7 \mathrm{a}$. The second step consists of checking whether the procedure of 
using good 1 (2) only for the production of characteristic 1 (2) produces at least the minimal levels of each good, i.e. to check whether $x_{1} \geq \bar{C}_{1} / \alpha$ (denoted as constraint $S_{1}$ ) and $x_{2} \geq \bar{C}_{2} / \delta$ (denoted as constraint $S_{2}$ ). If so, the candidate optimal bundle is indeed optimal. This is the case for bundle I in Figures 7 and 8, and for bundle II in Figure 7, as these bundles each time lies above constraints $S_{1}$ and $S_{2}$. As is clear from Figure 7, good 2 is thus a gross complement to good 1.

If the minimal levels are not achieved, as is the case for bundle II in Figure 8a, the consumer does take into account that good 1 can also be used to produce characteristic 2 . Thus, by (19) and (20), we now have the constraints $x_{1, I} \geq \bar{C}_{1} / \alpha$ (denoted as $\left.S_{1}{ }^{\prime}\right)$ and $x_{2} \geq\left(\bar{C}_{2} / \delta\right)-(\gamma / \delta)\left[x_{1}-x_{1, I}\right]$ (denoted as $\left.S_{2}{ }^{\prime}\right)$. One can represent these three-dimensional constraints in the $x_{1} x_{2}$ space for fixed levels of $x_{1, I}$. Two such constraints, for $x_{1, I}=\bar{C}_{1} / \alpha$ (Figure 9a) and for $x_{1, I}>\bar{C}_{1} / \alpha$ (Figure 9b), are represented in Figure 9. The feasible bundles are those in the gray area below the budget constraint and above the constraints $S_{1}$ ' and $S_{2}$ '. We assume that the consumer continues to have the preferences defined by equation (21), reflecting the assumption that the consumer continues to dislike using good 1 to produce characteristic 2. Figure 9 now makes clear that such a consumer always prefers to put $x_{1, I}=\bar{C}_{1} / \alpha$; in Figure $9 \mathrm{~b}$, the consumer who puts $x_{1, I}>\bar{C}_{1} / \alpha$ is worse off than in Figure 9a. It follows that the relevant constraints are $x_{1} \geq \bar{C}_{1} / \alpha$ (denoted as constraint $S_{1}$ ' in Figure $8 \mathrm{~b}$ ) and constraint $x_{2} \geq\left(\bar{C}_{2} / \delta\right)-(\gamma / \delta)\left[x_{1}-\left(\bar{C}_{1} / \alpha\right)\right]$ (denoted as constraint $S_{2}$ ' in Figure $8 \mathrm{~b}$ ). The consumer chooses bundle III in Figure $8 b$, and good 1 is a gross substitute for good 2 instead of a gross complement to it.

Admittedly in this example, there is a sudden change in consumer choice, where suddenly the constraint $S_{2}$ ' becomes relevant instead of constraint $S_{2}$, reflecting the assumption that good 1 is suddenly also used to produce characteristic 2 . In a more realistic example, as the consumer gets more and more tight on characteristic 2 , she considers good 1 as a better and better substitute for good 2 in producing characteristic 2. To conclude, the preference mapping in Figure 6 can be interpreted as having an approximate constraint for characteristic 2 directly build into it, as well as an approximate constraint for characteristic 1. The latter constraint assures that extra units of good 1 get used to produce characteristic 2 when the consumer gets tight on characteristic 2 . When this constraint is built directly into the preferences, it is reflected in indifference curves that lie close to one another and become nearly vertical for small levels of good 1. This in turn is in accordance with indifference curves that "fan out" (see Section 2.1). 
(a)

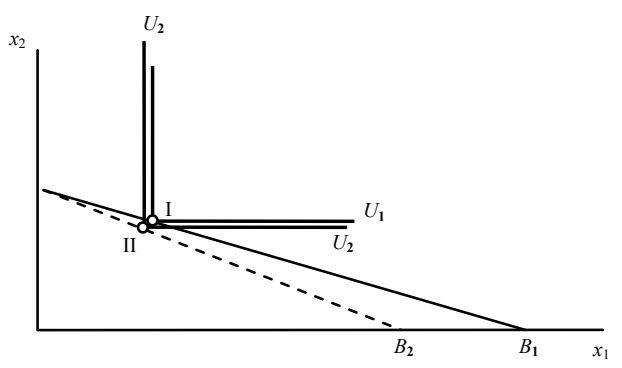

(b)

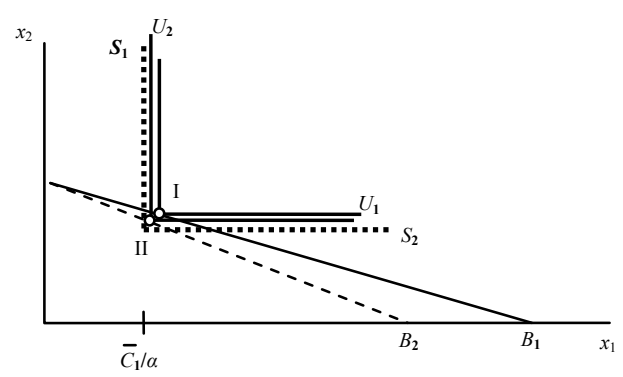

Figure 7 Good 2 is a complement to good 1

(a)

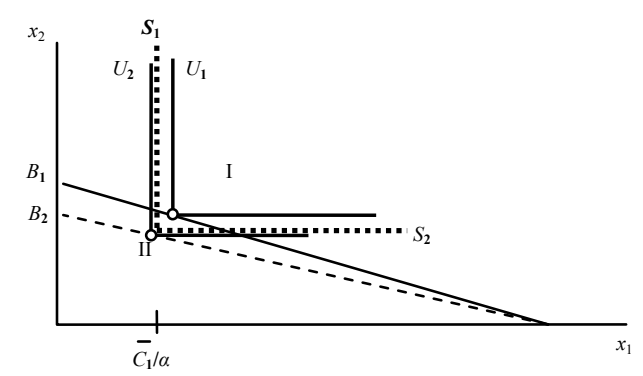

(b)

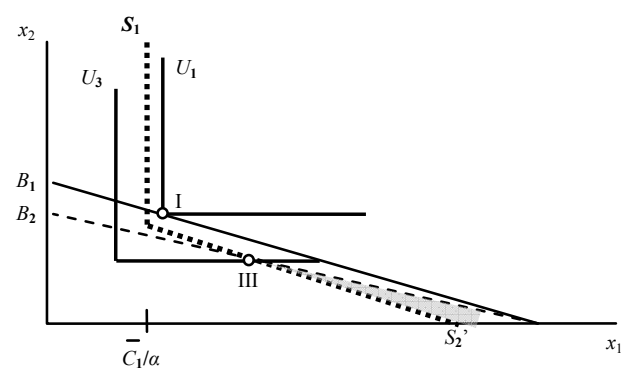

Figure 8 Good 1 is a substitute for good 2

(a)

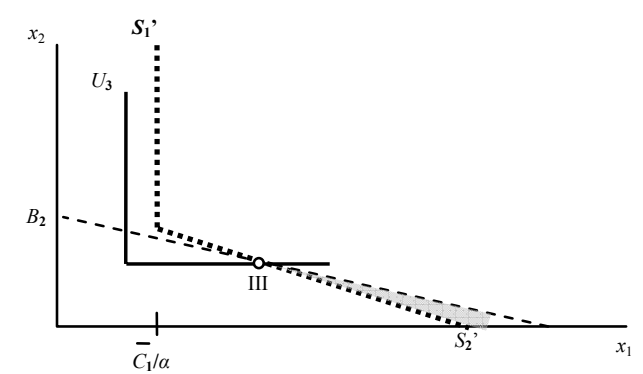

(b)

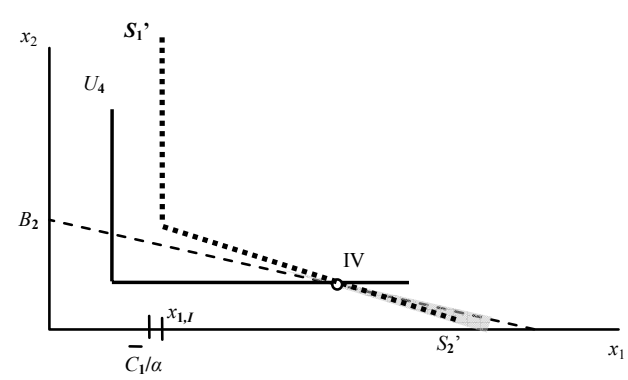

Figure 9 Constraints for two different levels of good 1 used to produce characteristic 1

\section{Potential examples and applications}

4.1 Giffen goods versus asymmetric substitutability in microeconomic education rice and meat

By equations (14) and (15), if good 1 is a Giffen good, then it is necessarily the case that goods 1 and 2 exhibit strong asymmetric gross substitutability, with good 1 a gross substitute for good 2, and good 2 a gross complement to good 1. This is no 
surprise, as the characteristics approach in Section 3.1 has been used by Jensen and Miller (2002) to explain the possibility of Giffen behavior, and the constraint approach explained in Section 3.1 has been used by Gilley and Karels (1991) with the same purpose.

In particular, in the analysis of Section 3.1, let good 1 be rice, and let good 2 be meat; let characteristic 1 be subsistence, and let characteristic 2 be taste. Rice is better at producing subsistence, and meat is better at producing taste. Let subsistence become relatively more important as the consumer's utility decreases. A rough approximation of this lies in Gilley and Karel's (1991) subsistence constraint, where consumers maximize utility with respect to the constraint that they must at least attain some minimum level of subsistence. When such a constraint is translated into preferences, it means that subsistence must become relatively more important when utility decreases. In such a case, it may be that, as meat becomes more expensive, the consumer substitutes rice for meat in order to subsist. As rice becomes cheaper, however, the consumer consumes both more rice and more meat to go with it.

As argued by Stigler (1947), Giffen goods are not empirically very plausible, and serve at best as a didactic exercise for students of economics to get insight into the decomposition of the own-price effect into substitution and income effects. Giffenity is certainly the exception rather than the rule, but even inferior goods are probably exceptional. Rather than exposing students to such exceptional cases, it may be an alternative to expose them to the empirically more plausible case of strong asymmetric gross substitutability, where good 1 is a gross substitute for good 2, and good 2 a gross complement to good 1. In terms of the characteristics approach in Section 3.1, the intuition is the same as for Giffenity, and the preference mapping has a similar shape, but one does not have a need to consider the exceptional cases of inferiority and Giffenity.

An indifference mapping exhibiting strong asymmetric gross substitutability, but where good 1 is an ordinary and a normal good, is represented in Figure 10. The consumer initially consumes bundle I. When the price of good 1 rises, in bundle II, less of good 2 is consumed, so that good 2 is a complement to good 1; less of good 1 is consumed, so that good 1 is an ordinary good. When the price of good 2 rises, in bundle III, more of good 1 is consumed, so that good 1 is a substitute for good 2 . When income decreases, in bundle IV, less of good 1 is consumed, so that good 1 is a normal good. 


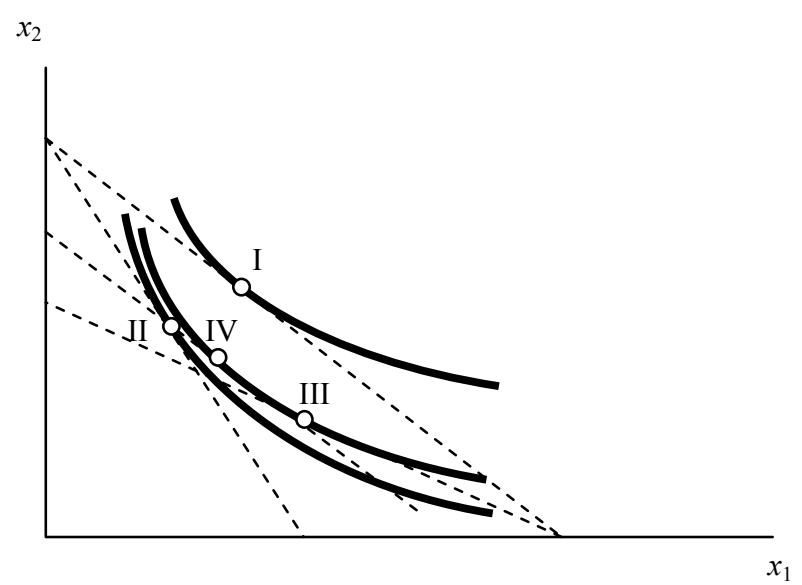

Figure 10 Preference mapping where goods exhibit asymmetric gross substitutability; both goods are normal and ordinary goods

An alternative treatment of consumer theory that avoids exceptional cases such as inferiority and Giffen behavior would start with homothetic preferences (goods are neither necessities nor luxuries), and point out that one has strong symmetric gross substitutability then, with goods either being mutual gross complements (both goods are price inelastic) or mutual gross substitutes (both goods are price elastic); see Figure 1a. The next step would then be to treat the case where one good is a luxury, and the other good is a necessity, and where goods are either mutual gross complements (both goods are price inelastic) or mutual gross substitutes (both goods are price elastic). In the case of mutual gross substitutes, the necessity is a stronger substitute for the luxury than the other way round. In the case of mutual gross complements, the luxury is a stronger complement for the luxury than the other way round. Such goods exhibit weak asymmetric gross substitutability, but not strong gross asymmetric substitutability. See Figure $1 \mathrm{~b}$ for such preferences. The final step would be to treat the case where good 1 is a necessity and good 2 a luxury, and where good 1 is a gross substitute for good 2, and good 2 is a gross complement to good 1 (strong asymmetric substitutability). Good 1 is then price inelastic, while good 2 is price elastic (see Figure 7). Specific about such an approach is that it treats the two goods involved simultaneously, rather than only focussing on good 1 .

4.2 Primary goods, secondary goods, and asymmetric effects of sales promotions: cake and cake frosting

Marketing research (e.g. Walters, 1991; Mulhern \& Leone, 1991; Manchanda et al. 1999) reveals asymmetric gross substitutability between pairs of primary goods and secondary goods, such as the pair cake mix/cake frosting. ${ }^{10}$ In particular, these studies reveal that cake frosting is a complement to cake, but that cake itself is neither a substitute for nor a complement to cake frosting.

This can be explained by the analysis in Section 3.1. Let a consumer value the two characteristics "satisfaction from eating" (characteristic 1) and "decoration" (characteristic 2). The consumer buys two goods. Good 1, cake mix, is best at producing the characteristic "satisfaction from eating"; good 2, cake frosting, is best

${ }^{10}$ Another example is laundry detergent (primary good) and fabric softener (secondary good) (Manchanda et al., 1999). 
at producing "decoration". As the consumer's utility is lower, "satisfaction from eating" becomes relatively more important. This is because the consumer wants a certain more or less fixed level of "satisfaction from eating". Such a fixed level can only be achieved if this characteristic becomes relatively more important as utility decreases. Cake mix is a necessity, and cake frosting is a luxury. Cake mix is neither a gross substitute nor a gross complement for cake frosting (see Figure 11a). Cake frosting is a gross complement to cake mix (see Figure 11b). Intuitively, when the price of cake frosting changes, the consumption of cake mix may not change, because the consumer wants to maintain about the same "satisfaction from eating". However, when the price of cake mix decreases, the consumer may buy both more cake mix and more cake frosting.

(a)

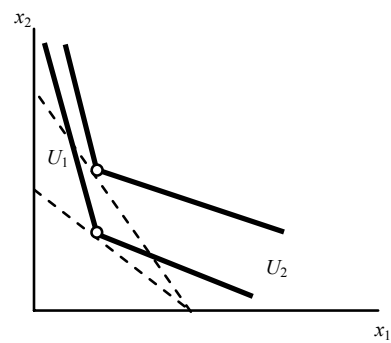

(b)

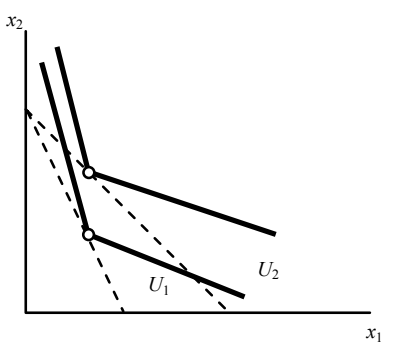

Figure 11 Good 1 (e.g., cake mix) is neither a substitute for, nor a complement to good 2; good 2 (e.g., cake frosting) is a complement to good 1.

Asymmetric gross substitutability has concrete consequences for the effectiveness of sales promotions. Clearly, for complements, one sales promotion can do the job of two, and managers can save costs by promoting only one of a pair of goods. But the possibility of asymmetric substitutability reveals that it may be that sales promotions need to be concentrated on a particular good within a pair of good. For instance, the sales promotion intended at boosting the sales of both cake mix and cake frosting should be focussed on cake mix, and not on cake frosting (Walters, 1991).

\subsection{Asymmetric substitutability of high-skilled and low-skilled labor}

While labor is the subject of production theory and not consumer theory, for expositional reasons; it is useful to look at an example that lies closer to labor economics than to consumer theory before treating an example in Section 4.4 that unambiguously lies in the realm of consumer theory. Moreover, labor is one of the few subjects where asymmetric substitutability is explicitly mentioned in the literature (e.g. Azariadis, 1975; Zon et al., 1998).

In accordance with the analysis in Section 3.2, let the dictatorial dean of a faculty maximize her utility given the faculty budget. The dean's utility function is defined over two characteristics, namely academic output (characteristic 1) and administrative output (characteristic 2). Academic output can only be produced by means of academics (good 1). Administrative output can be produced both by means of administrative personnel (good 2) and academics, even though the marginal administrative output of administrative personnel is higher. Note also that one 
working hour of an academic used for administration cannot at the same time be used for academic work.

As such, from the dean's perspective, academics and administrative personnel are mutual complements. However, at the same time, she wants to make sure that a minimum of academic output and of administrative work gets produced. If complementary use of administrative personnel and academics, where they each do the task at which they are best, causes a situation where not enough administrative output is produced, the dean may let academics do some of the administrative work. Thus, as illustrated in Figures 7 and 8, when the price of administrative personnel (good 2) increases, the dean may employ more academics (good 1), such that academics are a gross substitute for administrative personnel. However, when the price of academics decreases, the dean employs more academics, and more administrative personnel to go with it, such that administrative personnel is a gross complement to academic personnel.

Many studies of labor demand report that the demand for low-skilled labor is more elastic than the demand for high-skilled labour (e.g. Falk and Koebel, 2001 for shortrun labor demand). This seems to point towards asymmetric gross substitutability. ${ }^{11}$ Similar evidence lies in the tendency of employers to fire unskilled workers first during recessions. Skilled workers may be substituted for unskilled workers, where skilled workers during recessions would take over some of the tasks that would otherwise be done by unskilled workers (Reder, 1964, p.315).

\subsection{Asymmetric gross substitutability of all-in one-devices and special purpose devices and the definition of the market: mobile phones and fixed phones}

Strong asymmetric gross substitutability has recently been observed by Barros and Cadima (2000) and by Garbacz and Thomson (2007) for mobile phone services versus fixed phone services. A similar intuition to the one developed in Section 4.3, but now applied to a case that lies unambiguously in the realm of consumer theory, may help explain this phenomenon.

Let the utility of a consumer of phone calls depend on the characteristics "phone calls made outside of home" (characteristic 1), and "phone calls made at home" (characteristic 2). Let the consumer be able to produce these characteristics by means of mobile phone services (good 1) and of fixed phone services (good 2). Fixed phone services cannot produce calls outside of home, and thus do not contribute to the production of characteristic 1 . One can, however, use a mobile phone to call at home. This does not mean, however, that one will actually use a mobile phone both for calling outside and at home. In fact, as reported by Campbell (2001), the poorer the country, the higher the proportion of mobile phones with respect to fixed phones. This is in line with the characteristics model in Section 3.2. When the consumer is relatively well off, he or she uses mobile phones outside and fixed phones inside. However, when the consumer has less income, a minimum required number of phone calls at home may not be achieved if the consumer uses mobile phones only outside

\footnotetext{
${ }^{11}$ An altenative explanation of the fact that low-skilled labor is more elastic than high-skilled labor involves a third input, capital. For low-skilled labor, a close substitute is available in the form of capital, making low-skilled labor price elastic. On the other hand, capital is a complement to highskilled labor, making high-skilled labor less elastic. See Hamermesh, 1993. Footnote 9 above provides an analysis of this case, where good 1 is high-skilled labor, good 2 is low-skilled labor, and good 3 is capital. However, our explanation of asymmetric substitutability between high- and low-skilled labor continues to be relevant in the short run, where capital is fixed.
} 
and fixed phones only inside. In order to achieve a minimum number of calls at home, the consumer may then start to use her mobile phone more often at home. But why does the consumer then not use the fixed phone more often and the mobile phone less often? The reason is that such behaviour would again push the number of phone calls made outside, which can only be made with the mobile phone, below a minimum.

In general, candidates for pairs of goods that exhibit strong asymmetric gross substitutability are all-in-one devices versus special-purpose devices. This distinction appears to become more and more relevant. Consumers face the choice between buying a mobile phone with built-in MP3 player and/or digital camera, versus specialized and higher-quality MP3 players and GPS systems.

The possibility of strong asymmetric gross substitutability raises important questions regarding the concept of market power, and of the market itself. For a given good, the degree of market power in the provision of that good depends on the substitutes that are available for it (see Church and Ware, 2000, p.605). Thus, the fact that there is only one producer of cellophane is not a problem if close substitutes for cellophane are available, i.e. if the cross-price elasticity of a good like aluminium foil with respect to the price of cellophane is positive. However, this paper illustrates that substitutability need not be symmetric. Indeed, as argued by Banerjee (2007, pp.1617 ), in terms of the mobile phone/fixed phone services example, concentration of production of fixed phone services may not be problematic, as mobile phone services are a substitute. Mobile phone services are thus a part of the market for fixed phone services. But concentration of production of mobile phone services may be problematic, as there are no substitutes for mobile phone services. Fixed phone services are not part of the market for mobile services. Banerjee (2007) shows how in the US, the Federal Communications Commission made the mistake of concluding from the fact that mobile phone services are part of the market for fixed phone services, that fixed phone services are part of the market for mobile phone services. However, competition authorities in Europe do take into account the possibility of asymmetric substitutability in their definition of the market (see Market Definition in the Media Sector, 2002, p.267).

To our knowledge, the theory of industrial organization has not yet analyzed competition under asymmetric substitutability. The dominant model of competition under product differentiation is the one by Singh and Vives (1984). In their duopoly model, they assume that the representative consumer's three-good utility function is quasilinear in the third good, taking on the form $U\left(x_{1}, x_{2}\right)+x_{3}$. The authors study Cournot and Bertrand competition between goods 1 and 2; the function of the third good is to assure that there are zero income effect on both goods, so that the consumer surplus can be calculated for both the demand for good 1 and good 2. It is easy to show that goods 1 and 2 are necessarily strong symmetric gross substitutes (see Table 1) with Singh and Vives' utility function. Thus, not only does the dominant model not allow for strong asymmetric gross substitutability, it does not even allow for weak asymmetric gross substitutability. As shown in Section 2.1, any attempt to model competition in the case of weak or strong asymmetric gross substitutability will need to give up on the assumption of zero income effects, as there is a one-to-one relationship between weak asymmetric gross substitutability and asymmetry of the income effects. Thus, introducing a third good into the consumer's utility function when treating competition between two products has no sense in this case. Given that additionally the concept of consumer surplus cannot be used, a welfare analysis of competition between asymmetrically substitutable goods should make use of explicit 
utility functions. Some two-good utility functions that exhibit asymmetric substitutability are treated in De Jaegher (forthcoming).

\section{Discussion}

We started this paper by dinstinguishing between weak and strong asymmetric gross substitutability. In its weak form, asymmetric substitutability just means that cross-price effects are not the same. In its strong form, it means that cross-price effects have a different sign (good 1 is a substititute for good 2, and good 2 is a complement to good 1). It was shown that asymmetric substitutability occurs in circumstances that seem quite plausible. Weak asymmetric gross substitutability occurs as soon as one good is a necessity and the other good is a luxury; strong asymmetric gross substitutability occurs as soon as one good is price inelastic, and the other good is price elastic.

Still, while weak asymmetric substitutability seems intuitive, strong asymmetric gross substitutability seems at first sight unintuitive. We hope to have shown that there are clear intuitions for such a phenomenon, and to have attached plausible potential empirical examples to these intuitions. A first intuition is that the consumer consumes a primary good (e.g. cake mix) and a secondary good (e.g. cake frosting). It is the secondary good that is a complement to the primary good; the primary good is not a complement to the secondary good. On the contrary, the primary good may be a substitute for the secondary good. This is because the purpose served by the primary good (e.g. the purpose of satisfaction from eating, served by the cake mix), gains larger importance relative to the purpose served by the secondary good (e.g., the purpose of decoration served by cake frosting) as the utility of the consumer decreases; the reason for this is that the consumer wants to maintain a minimal level of satisfaction from eating. When the price of the secondary good increases, it may be that this can only be achieved by consuming less of the secondary good and more of the primary good.

A second intuition is that good 1 is best at doing job 1, while good 2 is best at doing job 2; however, good 1 is also able to do the job that good 2 normally does, even though it can do this job less well (good 2 is not able to do the job that is normally done by good 1). In normal circumstances, each good does its own job, and the two goods are complements. However, when the price of good 2 increases, it may be that too little output is obtained for the job normally done by good 2, and that good 1 is then exceptionally also used to do the job of good 2. Good 1 is thus a substitute for good 2. If the price of good 1 increases, enough of the job of good 2 gets done, so that good 2 continues to be a complement to good 1 . An example may be the following. If the price of mobile phone services increases, less mobile phone services and less fixed phone services are consumed. This is because fixed phones cannot substitute for mobile phones, as the former cannot be used to call outside of home. However, if the price of fixed phone services increases, more mobile phone services may be bought. This is because mobile phones will then also be used to call at home, a job that was otherwise done by fixed phones.

Applied microeconomic models often treat cases of weak symmetric gross substitutability (both goods are mutual gross substitutes, or mutual gross complements), or even of strong symmetric substitutability (the cross-price effects are equal, e.g. Singh and Vives, 1984). The analysis in this paper suggests that attention should also be paid to the possibility of asymmetric gross substitutability. The paper 
focuses on the two-good case, which clearly has limitations. However, we cannot hope to understand asymmetric substitutability in the multiple-good case if we do not at least understand the phenomenon in the two-good case.

\section{REFERENCES}

Allenby, G.M. \& P.E. Rossi. 1991. Quality perceptions and asymmetric switching between brands, Marketing Science 10, 185-204

Auspitz, R. \& R. Lieben. 1889. Untersuchungen über die Theorie des Preises, Duncker \& Humblot, Leipzig.

Azariadis, C. 1976. On the incidence of unemployment, Review of Economic Studies 43, 115-125.

Banerjee, A. 2007. ixed mobile substitution and lessons for broadband, paper presented at the Australian Competition and Consumer Commission's Regulatory Conference, July 26-27 2007, Gold Coast, Queensland, Australia.

Barros, P.P. \& N. Cadima (2000) The impact of mobile phone diffusion on the fixedline network, CEPR Discussion Paper Series No. 2598.

Campbell, D. 2001. Can the digital divide be contained, International Labour Review 140, 119-141.

Church, J. and R. Ware. 2000. Industrial Organization - a Strategic Approach, McGraw Hill, Boston.

De Jaegher, K. 2005. Benchmark two-good utility functions, The Manchester School, forthcoming.

Garbacz, C. and H.G. Thompson Jr. 2007. Demand for telecommunication services in developing countries, Telecommunications policy 31, 276-289.

Gilley, O.W. and G.V. Karels. 1991. In search of Giffen behavior. Economic Inquiry 29, 182-189.

Hamermesh, D.S. 1993. Labor Demand, Princeton University Press, Princeton.

Hicks, J. and R. Allen. 1934. A reconsideration of the theory of value, Parts I and II? Economica 1, 52-76, 196-219.

Jensen, R. and N. Miller. 2002. Giffen behavior: theory and evidence. John F. Kennedy School of Government, Harvard University, working paper.

Lancaster, K.J. (1966) A new approach to consumer theory, Journal of Political Economy 74, 132-157.

Lenfant, J.-S. 2003. In search of complementarity. Part 1, 1881-1915, working paper, Paris I University.

Lenfant, J.-S. 2006. Complementarity and demand theory - from the twenties to the forties. History of Political Economy 38: 48-85.

Manchanda, P., Ansari, A. and S. Gupta. 1999. The 'shopping basket' : a model for multicategory purchase incidence decisions. Marketing Science 18 (2), 95-114.

Market definition in the media sector - comparative legal analysis. 2000. Report by Bird \& Bird for the European Commision, DG competition.

Mulhern, F.J. \& Leone, R.P. 1991. Implicit price bundling of retail products - a multiproduct approach to maximizing store profitability. Journal of Marketing $55,63-76$.

Nicholson, W. 2005. Microeconomic Theory: Basic Principles and Extensions, $9^{\text {th }}$ Edition, Dryden Press, Fort Worth.

Reder, M.W. 1964. Wage structure and structural unemployment, Review of Economic Studies 31, 309-322. 
Roberts, M.J. and Skoufias, E. 1997. The long-run demand for skilled and unskilled labor in Colombian manufacturing plants, Review of Economics and Statistics, 79, 330-334.

Sethuraman, R., V. Srinivasan \& K. Doyle. 1999. Asymmetric and neighbourhood cross-price effects: some empirical generalizations, Marketing Science 18, 23-41.

Singh, N. and X. Vives. 1984. Price and quantity competition in a differentiated duopoly. Rand Journal of Economics 15, 546-554.

Stigler, G. 1947. Notes on the history of the Giffen paradox. Journal of Political Economy 55, 152-156.

Walters, R.G. 1991. Assessing the impact of retail price promotions on product substitution, complementary purchase, and interstore displacement, Journal of Marketing 55, 17-28.

Wichers, R. 1994. In search of Giffen behavior: comment. Economic Inquiry 32, 166167.

Zon, A. van, J. Muysken and H. Meijers. 1998. Asymmetric skill substitution, labour market flexibility, and the allocation of qualifications, in: H. Heijke and L. Borghans (Eds.) Towards a transparent labour market for educational decisions, London : Avebury Publishers.

\section{Appendix}

Denote by $|H|=\left|\begin{array}{ccc}u_{11} & u_{12} & -p_{1} \\ u_{21} & u_{22} & -p_{2} \\ -p_{1} & -p_{2} & 0\end{array}\right|$ the determinant of the bordered Hessian, and denote by $\lambda$ the Lagrangian multiplier. Applying Cramer's rule, we obtain that.

$\frac{\partial x_{1}}{\partial p_{2}}=\frac{\left|\begin{array}{ccc}0 & u_{12} & -p_{1} \\ \lambda & u_{22} & -p_{2} \\ x_{2} & -p_{2} & 0\end{array}\right|}{|H|}=\frac{\lambda p_{1} p_{2}}{|H|}+x_{2} \frac{\left|\begin{array}{cc}u_{12} & -p_{1} \\ u_{22} & -p_{2}\end{array}\right|}{|H|}=\frac{\lambda p_{1} p_{2}}{|H|}+\frac{x_{2}\left[-p_{2} u_{12}+p_{1} u_{22}\right]}{|H|}$

$\frac{\partial x_{2}}{\partial p_{1}}=\frac{\left|\begin{array}{ccc}u_{11} & \lambda & -p_{1} \\ u_{21} & 0 & -p_{2} \\ -p_{1} & x_{1} & 0\end{array}\right|}{|H|}=\frac{\lambda p_{1} p_{2}}{|H|}-x_{1} \frac{\left|\begin{array}{cc}u_{11} & -p_{1} \\ u_{21} & -p_{2}\end{array}\right|}{|H|}=\frac{\lambda p_{1} p_{2}}{|H|}-\frac{x_{1}\left[-p_{2} u_{11}+p_{1} u_{21}\right]}{|H|}$

Weak asymmetric substitutability, where $\frac{\partial x_{1}}{\partial p_{2}}>\frac{\partial x_{2}}{\partial p_{1}}$, is obtained if

$$
\begin{aligned}
& -x_{1}\left[-p_{2} u_{11}+p_{1} u_{21}\right]<x_{2}\left[-p_{2} u_{12}+p_{1} u_{22}\right] \\
& \Leftrightarrow \\
& -p_{1} x_{1} u_{21}+p_{2} x_{2} u_{12}<p_{1} x_{2} u_{22}-p_{2} x_{1} u_{11} \\
& \Leftrightarrow \\
& -\frac{x_{2} u_{22}}{u_{2}}+\frac{x_{2} u_{12}}{u_{1}}<-\frac{x_{1} u_{11}}{u_{1}}+\frac{x_{1} u_{21}}{u_{2}}
\end{aligned}
$$


where the (A4) is obtained from the fact that $u_{2} / u_{1}=p_{2} / p_{1} .-x_{i} u_{i i} / u_{i}$ is nothing but the relative risk-averseness of the consumer for good $i$ (with $i=1,2$ ), which again is a unit-free measure of the curvature of the utility function in good $i$ for given levels of good $j$. Thus, weak asymmetric substitutability is more likely to be obtained when the curvature of the utility function as a function of good 1 is larger than the curvature of the utility function as a function of good 2 (where the second term of the right- and the left-hand side of (A5) is assumed fixed). This is in line with Figure 1b, where the indifference curve lie at a higher distance from one another for changes in the consumption of good 1 than for changes in the consumption of good 2.

For an interpretation of the expressions on the right- and left-hand side of equation (A5), note that

$$
\begin{aligned}
& x_{1} \partial\left(u_{1} / u_{2}\right) / \partial x_{1}\left[\left(u_{1} / u_{2}\right)\right]^{-1}=x_{1} \frac{u_{11}}{u_{1}}-x_{1} \frac{u_{21}}{u_{2}} \\
& x_{2} \partial\left(u_{2} / u_{1}\right) / \partial x_{2}\left[\left(u_{2} / u_{1}\right)\right]^{-1}=x_{2} \frac{u_{22}}{u_{2}}-x_{2} \frac{u_{21}}{u_{1}}
\end{aligned}
$$

Thus, the right-hand side of (A5) is the absolute value of the elasticity of the marginal rate of substitution of good 1 for good 2 with respect to a change in consumption of good 1 (keeping consumption of good 2 fixed), while the left-hand side of (A5) is the elasticity of the marginal rate of substitution of good 2 for good 1 with respect to a change in consumption of good 2 (keeping consumption of good 1 fixed). With homothetic preferences, these elasticities are necessarily equal. It is also clear from this that weak asymmetric gross substitutability is obtained when the indifference curve "fan out". 